\title{
Congenital hyperinsulinism: clinical and molecular characterisation of compound heterozygous $A B C C 8$ mutation responsive to Diazoxide therapy
}

Ved Bhushan Arya ${ }^{1 \dagger}$, Qadeer Aziz $^{2 \dagger}$, Azizun Nessa ${ }^{3}$, Andrew Tinker ${ }^{2}$ and Khalid Hussain ${ }^{1,4^{*}}$

\begin{abstract}
Background: Mutations in ABCC8 and KCNJ11 are the most common cause of congenital hyperinsulinism (CHI). Recessive as well as dominant acting $A B C C 8 / K C N J 11$ mutations have been described. Diazoxide, which is the first line medication for $\mathrm{CH}$, is usually ineffective in recessive $A B C C 8$ mutations. We describe the clinical and molecular characterisation of a recessive $A B C C 8$ mutation in a $\mathrm{CHI}$ patient that is diazoxide response.

Clinical case: A term macrosomic female infant presented with symptomatic persistent hypoglycaemia confirmed to be secondary to $\mathrm{CHI}$. She exhibited an excellent response to moderate doses of diazoxide $(10 \mathrm{mg} / \mathrm{kg} / \mathrm{day})$. Molecular genetic analysis of the proband confirmed a biallelic ABCC8 mutation - missense R526C inherited from an unaffected mother and a frameshift c.1879delC mutation (H627Mfs*20) inherited from an unaffected father. Follow-up highlighted persistent requirement for diazoxide to control CHI. Functional analysis of mutants confirmed them to result in diazoxide-responsive $\mathrm{CH}$, consistent with the clinical phenotype.

Conclusion: Biallelic $A B C C 8$ mutations may result in diazoxide-responsive $\mathrm{CHI}$. Irrespective of the molecular genetic analysis results, accurate assessment of the response to diazoxide should be undertaken before classifying a patient as diazoxide-responsive or unresponsive $\mathrm{CHI}$.
\end{abstract}

Keywords: Congenital hyperinsulinism, Hypoglycaemia, ABCC8, Diazoxide

\section{Background}

Congenital hyperinsulinism (CHI) is due to an inappropriate insulin secretion by the $\beta$-cells of the islets of Langerhans [1]. It usually presents with severe hypoketotic hypofattyacidaemic hypoglycaemia [2]. The majority of the affected newborns are macrosomic at birth and require high intravenous glucose administration to maintain plasma glucose above $3.5 \mathrm{mmol} / \mathrm{l}[3]$.

Mutations in $A B C C 8$ and $K C N J 11$, which encode the SUR1 and Kir6.2 subunits of pancreatic ATP-sensitive potassium channel $\left(\mathrm{K}_{\mathrm{ATP}}\right)$, are by far the most common cause of $\mathrm{CHI}$ and are estimated to account for 36\%-69\%

\footnotetext{
* Correspondence: khalid.hussain@ucl.ac.uk

${ }^{\dagger}$ Equal contributors

'London centre for Paediatric Endocrinology, Great Ormond Street Hospital for Children NHS Foundation Trust, London WC1N 3JH and The Institute of Child Health, University College London, London WC1N 1EH, UK

${ }^{4}$ Developmental Endocrinology Research Group, Molecular Genetics Unit, Institute of Child Health, University College London, 30 Guilford Street, London WC1N 1EH, UK

Full list of author information is available at the end of the article
}

of all cases [4-6]. $\mathrm{K}_{\text {ATP }}$ channels are octameric protein complexes composed of four pore-forming Kir6.2 subunits and four sulfonylurea receptor 1 (SUR1) subunits, and form a link between cellular metabolism and membrane excitability $[7,8]$. It is thought that the $\beta$-cells in patients with $\mathrm{CHI}$ are persistently depolarized because of abnormally modulated or absent $\mathrm{K}_{\mathrm{ATP}}$ channels. This depolarisation opens the voltage-gated calcium channels and leads to unregulated insulin exocytosis. Although dominant acting $A B C C 8 / K C N J 11$ mutations have been reported, recessively inherited mutations are more common $[4,5,9,10]$.

Diazoxide, which binds to the SUR1 subunit of the $\mathrm{K}_{\text {ATP }}$ channel and reduces insulin secretion by hyperpolarisation of the pancreatic $\beta$-cell plasma membrane, is the first line of treatment for $\mathrm{CHI}$ [1]. However, recessive inactivating mutations in $A B C C 8$ and $K C N J 11$ usually cause severe diazoxide-unresponsive $\mathrm{CHI}$ due to defects in channel biogenesis, turnover, trafficking or regulation [11]. 
We describe a unique genotype-phenotype correlation with diazoxide responsive $\mathrm{CHI}$ in a patient with compound heterozygous $A B C C 8$ mutation. Functional work on the mutants was consistent with the observed clinical phenotype.

\section{Case presentation}

Clinical case

A term large-for-gestational age (birth weight $4500 \mathrm{~g}$ at 39 weeks gestation) female infant born to nonconsanguineous Caucasian parents presented with symptomatic hypoglycaemia on first day of life. There was no history of gestational diabetes mellitus in the mother. The proband developed tonic clonic seizures associated with laboratory blood glucose of $0.4 \mathrm{mmol} / \mathrm{l}$ at 22 hours of age. The infection and metabolic screen was negative. She required infusion of high concentration glucose (glucose infusion rate $16 \mathrm{mg} / \mathrm{kg} /$ minute) to maintain blood glucose above $3.5 \mathrm{mmol} / \mathrm{l}$.

A controlled hypoglycaemia screen established the diagnosis of $\mathrm{CHI}$ (serum Insulin $44.5 \mathrm{mU} / \mathrm{l}$ associated with lab glucose of $2.3 \mathrm{mmol} / \mathrm{l}$ and undetectable non-esterified fatty acids and $\beta$-hydroxybutyrate). Her serum cortisol was $570 \mathrm{nmol} / \mathrm{l}$ during the hypoglycaemia screen. The rest of the hypoglycaemic screen including insulin like growth factor-1 (IGF1), and insulin-like growth factor binding protein-3 (IGFBP3), serum ammonia, lactate, acylcarnitine profile, plasma amino acids and urine organic acids was within normal reference range (results not shown).

Molecular genetic analysis for $\mathrm{CHI}$ was performed after informed consent from the parents (see below). She was commenced on diazoxide $(5 \mathrm{mg} / \mathrm{kg} /$ day in three divided doses) and the dose was gradually increased to $10 \mathrm{mg} / \mathrm{kg} /$ day. Chlorothiazide was given along with diazoxide to counteract the side effect of fluid retention. On $10 \mathrm{mg} / \mathrm{kg} /$ day of diazoxide, she was successfully weaned off intravenous glucose administration. She demonstrated age appropriate fasting tolerance on diazoxide before discharge.

Blood glucose monitoring performed at home demonstrated satisfactory glycaemic control on diazoxide. No adjustment in diazoxide dose was required with her growth. At 9 months of age, a trial off diazoxide therapy resulted in recurrence of hypoglycaemia with fasting tolerance of only $3^{1 / 2}$ hours. Diazoxide was recommenced at $5 \mathrm{mg} / \mathrm{kg} /$ day, which led to disappearance of hypoglycaemia and age appropriate fasting tolerance.

At the time of writing, the proband is 15 months old and is able to fast for 12 hours without developing hypoglycaemia on a low dose of diazoxide $(5 \mathrm{mg} / \mathrm{kg} /$ day). Neurodevelopmental assessment did not identify any abnormality.

\section{Genetic analysis Methods}

Genomic DNA was extracted from peripheral blood leukocytes using standard procedures. The single exon of the KCNJ11 gene was amplified in 3 overlapping fragments and sequenced. When no mutations were identified in KCNJ11, the 39 exons of the $A B C C 8$ gene were amplified by polymerase chain reaction (PCR). The products were sequenced using Big Dye Terminator cycler sequencing Kit v3.1 (Applied Biosystems, Warrington, UK) and sequencing reactions were analysed on an ABI3730 (Applied Biosystems, Warrington, UK). Sequences were compared to the reference sequence (NM 000352.2) using Mutation Surveyor software (SoftGenetics, Pa., USA).

\section{Results}

Sequence analysis identified biallelic $A B C C 8$ mutation in the proband - a missense mutation, R526C, inherited from an unaffected mother and a frameshift mutation, c.1879delC (H627Mfs"20), inherited from an unaffected father. Both R526C and c.1879delC (H627Mfs*20) mutations have previously been reported as recessive acting mutations in patients with focal $\mathrm{CHI}$ [5].

\section{Functional analysis of mutant channels Methods}

Single point mutations (R526C and c.1879delC) were introduced into the hamster SUR1 clone by PCR using the Strategene XL Mutagenesis Kit according to the manufacturer's instructions.

Human Embryonic Kidney (HEK) 293 cells were transiently transfected with Kir6.2/SUR1, Kir6.2/SUR1c1879delC, Kir6.2/SUR1R526C or Kir6.2/SUR1c1879C + SUR1R526C (together with a small amount of eGFP (Green Fluorescence Protein) expressing plasmid to enable identification of transfected cells using epifluorescence) using FuGENE HD (Roche Diagnostics, UK) as per the manufacturers' instructions and cells were subjected to whole cell patchclamp 48 hours after transfection.

Whole-cell patch-clamp recordings were performed as previously described [12]. Capacitance transients and series resistance in whole-cell recordings were compensated electronically by using amplifier circuitry (Multiclamp 700B). Data were filtered at $1 \mathrm{kHz}$ using the filter provided with the Multiclamp 700B (4 pole Bessel) and sampled at $5 \mathrm{kHz}$ using a Digidata 1440 (Axon Instruments). Currents were acquired and analysed using pClamp 10.4 (Axon Instruments). The intracellular (pipette) solution contained (mM); $140 \mathrm{KCl}, 1.2 \mathrm{MgCl}_{2}, 1 \mathrm{CaCl}_{2}, 10$ EGTA and 5 HEPES, $0.1 \mathrm{mM} \mathrm{Na.ATP}$ and $1 \mathrm{mM}$ Na.ADP, $\mathrm{pH} 7.2$ using $\mathrm{KOH}$. The bath solution contained (mM); 5 $\mathrm{KCl}, 140 \mathrm{NaCl}, 2.6 \mathrm{CaCl}_{2}, 1.2 \mathrm{MgCl}_{2}$ and 5 HEPES (pH 7.4). Pipette resistances were between 2-4 $\mathrm{m} \Omega$. Diazoxide and Tolbutamide were obtained from Sigma Aldrich (Poole, UK). Agents were applied to the bath using a gravity-driven perfusion system. 
Results

Whole-cell patch-clamp recordings from HEK 293 cells transfected with wild-type (WT) Kir6.2/SUR1 cDNA showed normal $K_{\text {ATP }}$ currents which was activated by the $\mathrm{K}_{\mathrm{ATP}}$ channel opener diazoxide $(100 \mu \mathrm{M})$ and inhibited by the $\mathrm{K}_{\text {ATP }}$ blocker tolbutamide $(100 \mu \mathrm{M})$ (control, $144.77 \pm 25.57 \mathrm{pA} / \mathrm{pF} ;$ diazoxide, $382.7 \pm 37.67 \mathrm{pA} / \mathrm{pF}$; diazoxide + tolbutamide, $98.05 \pm 28.05 \mathrm{pA} / \mathrm{pF}, \mathrm{n}=5$ cells, $\mathrm{P}<0.05)$. Currents from cells transfected with the frameshift mutation SUR1c1879delC were unresponsive to diazoxide and tolbutamide (control, 85.26 $\pm 12.7 \mathrm{pA} / \mathrm{pF}$; diazoxide, $91.98 \pm 14.36 \mathrm{pA} / \mathrm{pF}$; tolbutamide, $79.57 \pm 11.57 \mathrm{pA} / \mathrm{pF}, \mathrm{n}=7$ cells, $\mathrm{P}>0.05)$. In contrast, currents from cells transfected with the missense mutation, SUR1R526C, activated in the presence of diazoxide albeit to a lesser extent when compared to WT (control, $76.55 \pm 8.2 \mathrm{pA} / \mathrm{pF}$; diazoxide, $175.2 \pm 16.47 \mathrm{pA} / \mathrm{pF}$; tolbutamide, $64.55 \pm 8.88 \mathrm{pA} / \mathrm{pF}, \mathrm{n}=5$ cells, $\mathrm{P}<0.05)$.

Interestingly, co-expression of SUR1c1879delC and SUR1R526C (to mimic the compound heterozygous $A B C C 8$ (R256C/H627Mfs*20) mutation) rescued the diazoxidesensitive $\mathrm{K}_{\mathrm{ATP}}$ current which was absent when SUR1c1879delC was expressed alone (control, 62.9 $\pm 9.3 \mathrm{pA} / \mathrm{pF}$; diazoxide, $223.11 \pm 60.21 \mathrm{pA} / \mathrm{pF}$; tolbutamide, $52.26 \pm 11.36$ $\mathrm{pA} / \mathrm{pF}, \mathrm{n}=5$ cells, $\mathrm{P}<0.05)$. These data are shown in Figure 1. The diazoxide-sensitive $\mathrm{K}_{\text {ATP }}$ current in the double mutant transfected cells was significantly greater as compared to SUR1c1879delC transfected cells $(160.2 \pm 52.9$ vs $8.72 \pm$ $4.41 \mathrm{pA} / \mathrm{pF}, \mathrm{P}=0.01$ ) and equivalent to $\mathrm{WT}$ Kir6.2/SUR1 transfected cells $(160.2 \pm 52.9$ vs $237.9 \pm 59.1 \mathrm{pA} / \mathrm{pF}, \mathrm{P}=0.33)$.

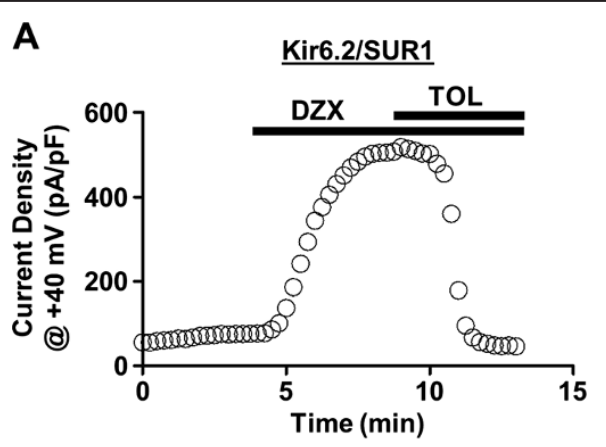

Kir6.2/SUR1c1879delC

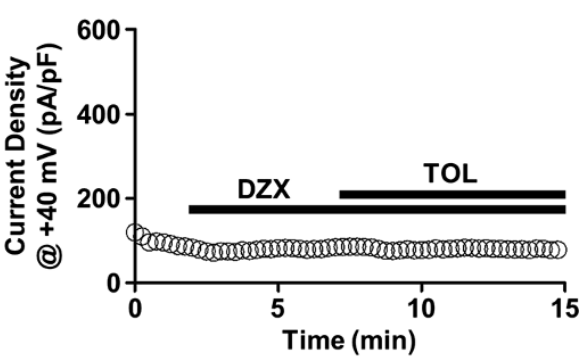

Kir6.2/SUR1R526C+
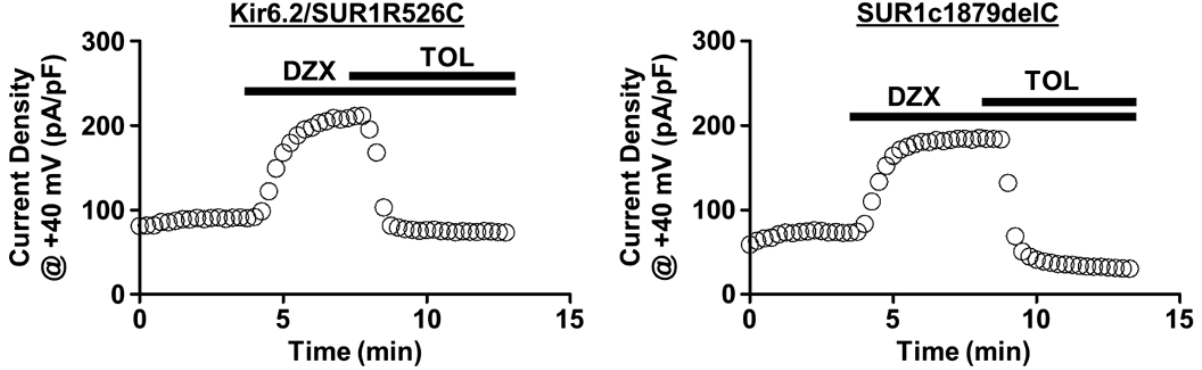

B

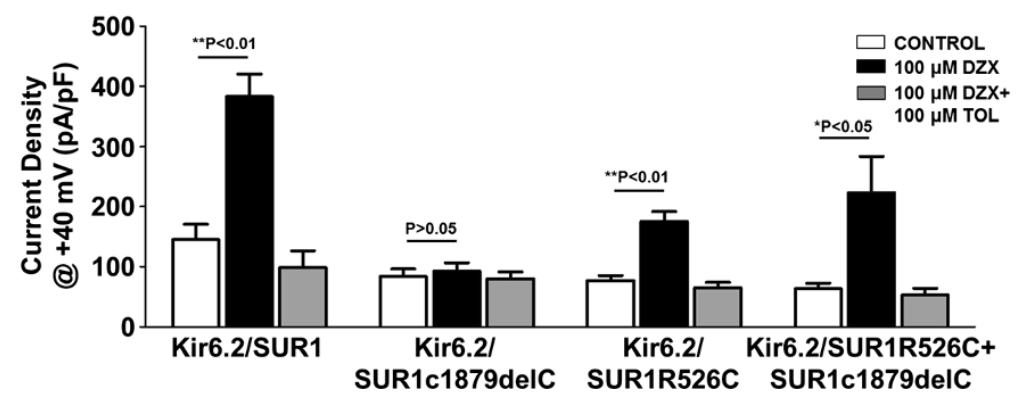

Figure 1 Functional characterisation of $\mathrm{K}_{\mathrm{ATP}}$ channels with a heterozygous $A B C \mathrm{~B} 8 \mathrm{R} 526 \mathrm{C} / \mathrm{H} 627 \mathrm{Mfs}{ }^{*} 20$ compound mutation. A, Representative whole-cell time-current density traces at $+40 \mathrm{mV}$ recorded from HEK293 cells expressing Kir6.2/SUR1, Kir6.2/SUR1c1879delC, Kir6.2/SUR1R526C and Kir6.2/SUR1R526C + SUR1C1879delC showing the effects of diazoxide (DZX) and tolbutamide (in the presence of diazoxide) (TOL). Current were recorded using a $1 \mathrm{~s}$ ramp protocol $(-150 \mathrm{mV}$ to $50 \mathrm{mV}$ ). B, Summary of the mean current-densities at $+40 \mathrm{mV}$. Values are mean \pm S.E.M from $5-7$ cells, ${ }^{*} \mathrm{P}<0.05,{ }^{*} \mathrm{P}<0.01$ compared to control 
There was no statistically significant difference in the $\mathrm{K}_{\text {ATP }}$ current seen in cells transfected with SUR1R256C alone and cells co-transfected with SUR1R256C and SUR1c1879delC ( $\mathrm{p}=0.291)$.

\section{Discussion}

We describe a patient with diazoxide responsive $\mathrm{CHI}$ due to compound heterozygous $A B C C 8$ mutation. The proband was macrosomic at birth (consistent with foetal hyperinsulinism) and presented with severe hypoketotic hypoglycaemia requiring high glucose infusion $(16 \mathrm{mg} / \mathrm{kg} /$ minute). Investigations confirmed $\mathrm{CHI}$ and compound heterozygous ABCC8 (R256C/H627Mfs*20) mutation. Surprisingly, the proband showed an excellent response to moderate doses of diazoxide $(10 \mathrm{mg} / \mathrm{kg} /$ day $)$. Subsequent follow-up revealed persistent requirement for diazoxide to control CHI. Functional analysis of the mutant $\mathrm{K}_{\text {ATP }}$ channel subunits confirmed a phenotype of diazoxide-responsive $\mathrm{CHI}$ in association with $A B C C 8 \mathrm{R} 526 \mathrm{C} / \mathrm{H} 627 \mathrm{Mfs}$ *20 compound heterozygous mutation.

Mutations in $A B C C 8$ and $K C N J 11$, both monoallelic and biallelic, account for the majority of $\mathrm{CHI}$ patients $[4,5]$. Although monoallelic ABCC8/KCNJ11 mutations can cause both diazoxide-responsive as well as diazoxideunresponsive $\mathrm{CHI}$, nearly all biallelic $A B C C 8 / K C N J 11 \mathrm{mu}-$ tations result in diazoxide unresponsive $\mathrm{CHI}[9,10,13,14]$. In two recent large studies comprising more than 700 patients with $\mathrm{CHI}$, there was no patient reported with diazoxide responsive $\mathrm{CHI}$ due to biallelic $A B C C 8 / K C N J 11$ mutation $[4,5]$.

However, Dekel et al. reported a patient with a compound heterozygous $A B C C 8$ mutation (c.3992-9G > A/ F1388del) who responded to diazoxide [15]. However, no functional work was done to correlate with the clinical observations.

Previous functional work on compound heterozygous $A B C C 8$ mutations has shown that mutations may interact to modify $\mathrm{K}_{\mathrm{ATP}}$ channel function and influence disease severity. Muzyamba et al. showed that single SUR1 mutants (D1193V or R1436Q) trafficked to the plasma membrane whereas the double mutant (SUR1D1193V/ $\mathrm{R} 1436 \mathrm{Q})$ was retained in the endoplasmic reticulum [16].

Both SUR1 R526C and H627Mfs*20 mutations have been described previously as presumed recessive acting mutations in association with CHI. Snider et al. reported one patient each with both these mutations in association with focal CHI [5]. No functional work had been done on either of these mutations. The H627Mfs*20 mutation is a frameshift mutation and is severely damaging to the protein function as shown by our functional work. When the SUR1H627Mfs*20 mutant was co-expressed with Kir6.2, there was no increase in current with the application of diazoxide indicating either absence of $\mathrm{K}_{\mathrm{ATP}}$ channels on the plasma membrane surface and $\mid$ or severely dysfunctional $\mathrm{K}_{\mathrm{ATP}}$ channel. With the SUR1R526C mutant, there was reduced current flow under basal conditions as compared to wild-type. However, importantly, there was an increase in current with the application of diazoxide which persisted when the two mutants (SUR1R526C/H627Mfs*20) were expressed in combination, suggesting this variant to be diazoxide-responsive.

As the frameshift mutation H627Mfs*20 results in a premature termination codon and is likely to be degraded by non-sense mediated decay, it is possible that the $\mathrm{K}_{\mathrm{ATP}}$ channels in double mutant SUR1R256C/H627Mfs*20 will contain SUR1 subunits produced by allele carrying R526C mutation only and hence the response shown by the SUR1R256C/H627Mfs*20 resembles that of SUR1R256C mutant. However non-sense mediated decay cannot be reproduced in the expression studies as that requires replication of intronic and exonic structure of the gene whereas the plasmids can only accommodate cDNA of the gene.

Although we used $100 \mu \mathrm{M}$ diazoxide to assess the responsiveness of SUR1 mutants, to our knowledge there is no data in the literature as to what concentration of diazoxide is achieved at the cellular level with the standard doses of diazoxide used for medical management of $\mathrm{CHI}$. However, assuming a distribution volume of $\sim 0.2 \mathrm{~L} / \mathrm{kg}$, the dose of diazoxide administered orally to this proband is likely to result in a concentration higher $(\sim 2 \times)$ than the $100 \mu \mathrm{M}$ we used for our studies at the cellular level [17].

Our functional data, however, is not consistent with the previous observation of diazoxide-unresponsive focal $\mathrm{CHI}$ in association with paternally inherited heterozygous $A B C C 8$ R526C mutation [5]. Marked intrafamilial clinical heterogeneity in four haploidentical siblings harbouring the identical $A B C C 8$ homozygous c.3992-9G > A mutation was also highlighted by Kapoor et al. [18]. This difference in clinical expression may be due to background genetic factors and other unknown factors involved in regulating gene expression.

\section{Conclusion}

In conclusion, although the majority of biallelic $A B C C 8 /$ KCNJ11 mutations result in diazoxide-unresponsive $\mathrm{CHI}$, occasional biallelic and particularly compound heterozygous $A B C C 8$ mutations may lead to a diazoxide-responsive phenotype. Accurate clinical assessment would avoid the need for near-total pancreatectomy in such cases.

\section{Consent}

Written informed consent was obtained from the patient for publication of this Case report and any accompanying images. A copy of the written consent is available for review by the Editor-in-Chief of this journal. 


\section{Abbreviations}

CHI: Congenital hyperinsulinism; KATP: Potassium sensitive ATP channel; SUR1: Sulfonylurea receptor 1; IGF1: Insulin-like growth factor 1; IGFBP3: IGF binding protein 3; PCR: Polymerase chain reaction; HEK 293 cells: Human Embryonic Kidney 293 cells; GFP: Green Fluorescence Protein; WT: Wild type.

\section{Competing interests}

The authors declare that they have no competing interests.

\section{Authors' contributions}

VBA contributed to acquisition of data and drafted the manuscript. QA performed the experiments, analyzed and interpreted the data and helped in drafting the manuscript. AN contributed to interpretation of data and revising it critically for important intellectual content. AT contributed to analysis and interpretation of data and revising it critically for important intellectual content. $\mathrm{KH}$ contributed to analysis and interpretation of data and revising it critically for important intellectual content. All authors read and approved the final manuscript.

\section{Acknowledgements}

The authors would like to acknowledge Dr Sarah E. Flanagan and Prof Sian Ellard from University of Exeter Medical School for contribution towards genetic testing. There is no source of funding for this manuscript preparation.

\section{Author details}

${ }^{1}$ London centre for Paediatric Endocrinology, Great Ormond Street Hospital for Children NHS Foundation Trust, London WC1N 3JH and The Institute of Child Health, University College London, London WC1N 1EH, UK. ${ }^{2}$ The Heart Centre, William Harvey Research Institute, Barts and the London School of Medicine and Dentistry, Charterhouse Square, London, UK. ${ }^{3}$ The Institute of Child Health, University College London, London WC1N 1EH, UK. ${ }^{4}$ Developmental Endocrinology Research Group, Molecular Genetics Unit, Institute of Child Health, University College London, 30 Guilford Street, London WC1N 1EH, UK.

Received: 21 August 2014 Accepted: 25 November 2014 Published: 15 December 2014

\section{References}

1. Aynsley-Green A, Hussain K, Hall J, Saudubray JM, Nihoul-Fekete C, De Lonlay-Debeney P, Brunelle F, Otonkoski T, Thornton P, Lindley KJ: Practical management of hyperinsulinism in infancy. Arch Dis Child Fetal Neonatal Ed 2000, 82:F98-F107.

2. Hussain K, Blankenstein O, De Lonlay P, Christesen HT: Hyperinsulinaemic hypoglycaemia: biochemical basis and the importance of maintaining normoglycaemia during management. Arch Dis Child 2007, 92:568-570.

3. Arya VB, Mohammed Z, Blankenstein O, De Lonlay P, Hussain K. Hyperinsulinaemic hypoglycaemia. Horm Metab Res 2014, 46:157-170.

4. Kapoor RR, Flanagan SE, Arya VB, Shield JP, Ellard S, Hussain K: Clinical and molecular characterisation of 300 patients with congenital hyperinsulinism. Eur J Endocrinol 2013, 168:557-564.

5. Snider KE, Becker S, Boyajian L, Shyng SL, MacMullen C, Hughes N, Ganapathy K, Bhatti T, Stanley CA, Ganguly A: Genotype and phenotype correlations in 417 children with congenital hyperinsulinism. J Clin Endocrinol Metab 2013, 98:E355-E363.

6. Demirbilek H, Arya VB, Ozbek MN, Akinci A, Dogan M, Demirel F, Houghton J, Kaba S, Guzel F, Baran RT, Unal S, Tekkes S, Flanagan SE, Ellard S, Hussain K: Clinical characteristics and phenotype-genotype analysis in Turkish patients with congenital hyperinsulinism; predominance of recessive KATP channel mutations. Eur J Endocrinol 2014, 170(6):885-892.

7. Shyng S, Nichols CG: Octameric stoichiometry of the KATP channel complex. J Gen Physiol 1997, 110:655-664.

8. Ashcroft FM: ATP-sensitive potassium channelopathies: focus on insulin secretion. J Clin Invest 2005, 115:2047-2058.

9. Kapoor RR, Flanagan SE, James CT, McKiernan J, Thomas AM, Harmer SC Shield JP, Tinker A, Ellard S, Hussain K: Hyperinsulinaemic hypoglycaemia and diabetes mellitus due to dominant $A B C C 8 / K C N J 11$ mutations. Diabetologia 2011, 54:2575-2583.

10. Huopio H, Reimann F, Ashfield R, Komulainen J, Lenko HL, Rahier J, Vauhkonen I, Kere J, Laakso M, Ashcroft F, Otonkoski T: Dominantly inherited hyperinsulinism caused by a mutation in the sulfonylurea receptor type 1. J Clin Invest 2000, 106:897-906.

11. James C, Kapoor RR, Ismail D, Hussain K: The genetic basis of congenital hyperinsulinism. J Med Genet 2009, 46:289-299.

12. Aziz Q, Thomas AM, Khambra T, Tinker A: Regulation of the ATP-sensitive potassium channel subunit, Kir6.2, by a Ca2+-dependent protein kinase. C. J Biol Chem 2012, 287:6196-6207.

13. Pinney SE, MacMullen C, Becker S, Lin YW, Hanna C, Thornton P, Ganguly A, Shyng SL, Stanley CA: Clinical characteristics and biochemical mechanisms of congenital hyperinsulinism associated with dominant KATP channel mutations. J Clin Invest 2008, 118:2877-2886.

14. Macmullen CM, Zhou Q, Snider KE, Tewson PH, Becker SA, Aziz AR, Ganguly A, Shyng SL, Stanley CA: Diazoxide-unresponsive congenital hyperinsulinism in children with dominant mutations of the beta-cell sulfonylurea receptor SUR1. Diabetes 2011, 60:1797-1804.

15. Dekel B, Lubin D, Modan-Moses D, Quint J, Glaser B, Meyerovitch J: Compound heterozygosity for the common sulfonylurea receptor mutations can cause mild diazoxide-sensitive hyperinsulinism. Clin Pediatr (Phila) 2002, 41:183-186.

16. Muzyamba M, Farzaneh T, Behe P, Thomas A, Christesen HB, Brusgaard K, Hussain $\mathrm{K}$, Tinker A: Complex ABCC8 DNA variations in congenital hyperinsulinism: lessons from functional studies. Clin Endocrinol (Oxf) 2007, 67:115-124.

17. Ogilvie Rl, Nadeau JH, Sitar DS: Diazoxide concentration-response relation in hypertension. Hypertension 1982, 4:167-173.

18. Kapoor RR, Flanagan SE, Ellard S, Hussain K: Congenital hyperinsulinism: marked clinical heterogeneity in siblings with identical mutations in the ABCC8 gene. Clin Endocrinol (Oxf) 2012, 76:312-313.

doi:10.1186/1687-9856-2014-24

Cite this article as: Arya et al:: Congenital hyperinsulinism: clinical and molecular characterisation of compound heterozygous $A B C C 8$ mutation responsive to Diazoxide therapy. International Journal of Pediatric Endocrinology 2014 2014:24.

\section{Submit your next manuscript to BioMed Central and take full advantage of:}

- Convenient online submission

- Thorough peer review

- No space constraints or color figure charges

- Immediate publication on acceptance

- Inclusion in PubMed, CAS, Scopus and Google Scholar

- Research which is freely available for redistribution 